\title{
EL ESTADO EN CUBA. REFLEXIONES EN TORNO A SU ENCARGO SOCIAL EN RELACION CON LAS FAMILIAS
}

\author{
YANESY DE LA CARIDAD SERRANO LORENZO ${ }^{1}$ \\ Universidad Central "Marta Abreu" de las Villas (UCLV). Carretera a Camajuani km \\ 51/2. Municipio de Santa Clara. \\ Código Postal, 50100, Provincia Villa Clara, Cuba. \\ Yanesy@uclv.edu.co
}

\section{RESUMEN}

El debate académico en Cuba ha aportado hasta el presente, reflexiones sobre cómo se ha abordado el tema de la contribución del Estado cubano a la vida en familias. Se propone una reflexión en torno a la temática del Estado en Cuba y su encargo social en relación con las familias. Se precisan aspectos relacionados al sistema político y el Estado así como el papel que le corresponde a las sociedades en el desarrollo y bienestar de las familias, a través de las responsabilidades estatales, principios, vías y actores sociales que de una manera u otra deben conectarse en el trazado y puesta en práctica de acciones hacia el grupo e institución familiar. Posteriormente, se abordan elementos relacionados con el encargo social del Estado en relación a las familias en el contexto cubano y finalmente, se expresan algunos de los desafíos que posee el proyecto social ante la presente heterogeneidad familiar.

Palabras clave: Estado-Familia-responsabilidades estatales-principios-víasactores sociales.

1 Doctora en Ciencias Sociológicas. Profesora e investigadora Titular del Centro de Estudios Comunitarios (CEC). Universidad Central "Marta Abreu" de las Villas (UCLV). 
THE STATE IN CUBA. ANALYSIS ABOUT ITS SOCIAL DUTY IN RELATION TO FAMILIES

\section{ABSTRACT}

The academic debate in Cuba has provided, until the present days, deep analysis of how has been approached the topic of the contribution of the Cuban State in the life of families. Some aspects related to the political system and to the state are treated, as well as the role that corresponds to the societies in the development and wellbeing of families through state responsibilities, principles, ways and social actors who in one way or another should be connected to the layout and implementation of actions towards the group and family institution. Subsequently, some elements related to the social function of the State are also treated in relation to the family in the Cuban context and finally, are stated some of the challenges that the social project has in the current family heterogeneity.

Keywords. State- family- state responsibilities- principles- ways-social actors.

\section{Introducción}

Las familias son consideradas universalmente como células básicas de la sociedad por su papel en los procesos de reproducción social. Son institutos socializadores de la personalidad, únicos por su especificidad de ser al mismo tiempo, instituciones y grupos sociales primarios que cumplen importantes funciones para el desarrollo de la sociedad y de las personas que las integran.

Como parte de la estructura social, las familias surgieron diferenciándose por la división sexual del trabajo. A su vez, a lo largo de la historia han pautado relaciones entre sus miembros dejando su impronta en disímiles culturas, civilizaciones, clases sociales, razas, regiones, continentes, zonas rurales y urbanas de diferentes maneras.

La importancia de estudiar a las familias en la actualidad, se refleja en las investigaciones y espacios de debate científico así como en la preocupación y ocupación de los Estados. Ello, precisamente porque en las familias se producen y reproducen la vida de las personas. Es en el seno familiar donde se reproducen 
pautas saludables o distorsionadoras de los procesos de aprendizaje de vida, lugar de choque y de cambio respecto al orden social.

Desde la perspectiva sociológica, se aborda el encargo social del Estado en relación con las familias, adentrándose en el análisis del objeto de indagación científica en el contexto cubano. En este trabajo se da cuenta de la pregunta:

¿Son proyectadas y analizadas las familias en Cuba desde sus complejidades o siguen siendo valoradas desde el Estado con acciones sectorializadas hacia sus miembros y no en su integralidad?.

Esta interrogante permite acercarnos al tema, con puntos de vistas más holísticos e integrales del asunto, posicionándonos en la idea que constituye una urgencia desde el proyecto social cubano, proyectarse hacia las familias desde su heterogeneidad.

\section{Una mirada sociológica a la temática del Estado}

Referirse al encargo social del Estado en relación con las familias, implica comprender el papel del Estado y sus instituciones en la toma de decisiones y en la concreción de acciones orientadoras de intervención en los asuntos de familias.

Remitirse a esta temática, permite acercarse en primer lugar al sistema político. Sus aproximaciones se han movido fundamentalmente dentro de la corriente estructural funcionalista, las definiciones ofrecidas por sociólogos y politólogos como T. Parsons, M. Duverger, H. Wiseman, Huntington, M. Kaplan, Debbach, A. Etzioni, entre otros, poseen como denominador común las relaciones políticas.

Desde la teoría marxista, aunque Carlos Marx utiliza en algunas ocasiones "régimen político" y "superestructura política", no existen en su obra siguiendo a Fung y Rodríguez (2000), "determinaciones de dichos fenómenos que los distingan completamente, pues trabaja con totalidades sociales como la formación económico-social, donde se establecen jerarquizaciones e instancias de condicionamiento a un nivel macro" (p.5).

Sustentada en posiciones epistémicas y en un nuevo contexto signado por la globalización, se coincide en la definición que proponen Fung y Rodríguez (2000) quienes se refieren al sistema político como: 
El conjunto de interrelaciones políticas objetivas (entre instituciones, Estado, partidos, grupos de presión, grupos de interés, clases sociales, organizaciones internacionales y nacionales, económicas, científicas, medioambientales y culturales) y subjetivas (normas, conciencias, tradiciones, culturas políticas, formación de políticas, toma de decisiones) tendentes a una organización sistémica de la producción y reproducción del poder societario y al ejercicio de su distribución sobre la base del equilibrio. (P.10)

Es el sistema político estructurado fundamentalmente en sociedad política y sociedad civil, desempeñando un papel esencial el Estado ${ }^{2}$

(...) como representante y defensor de la soberanía nacional e integración nacional, coordinador de la actividad económica, diseñador y promotor de estrategias de desarrollo y de la política social, de la cultura y la ideología dominante así como de la preservación del orden público y seguridad ciudadana" (...). (Valdés, 2000, p.35)

El carácter soberano del Estado indica que resulta superior a cualquier otro poder existente, de ahí que se le considere el principal instrumento de poder al concentrar en sí mecanismos de coerción y fuerza que operan en el ámbito de toda la sociedad, lo que lo convierte en medio de dominación y de integración social.

Es a su vez el Estado, "una estructura organizativa de carácter jurídico, normativo y coercitivo, a través de la cual éste logra un orden que hace posible su estabilidad, su funcionamiento (económico, social, político), su reproducción en el tiempo y la orientación de su desarrollo" (Espina, 2008, p.20).

A partir de la Sociología, el programa de los sociólogos proponía un conjunto de transformaciones con la finalidad de ordenar y estabilizar el sistema planteado por la clase burguesa dominante. Sus ideas se presentan desde el cambio social a partir de la reforma y el diseño de un grupo de conceptos que pueden ser ubicados como conservadores.

Para el sociólogo francés A. Comte (1957) el Estado era el "líder social y garante del equilibrio" (p.40), como defensor del también orden capitalista. Emile Durkheim (1858-1917), coloca al Estado como "la institución social que se encarga de representar al cuerpo social en su conjunto y dirigirlo en la búsqueda del progreso" (Durkheim, 1931, p.25). El Estado posee la fuerza y la capacidad

\footnotetext{
${ }^{2}$ Su vocablo proviene del latín status, que significa orden, regla, situación jerarquizada que permanece.
} 
necesarias para ejercer el control y la mediación en las sociedades modernas. Debe "controlar todas las esferas de la vida social y vigilar cualquier conducta anómica que afecte la cohesión del organismo social" (Durkheim, 1931, p.26).

Para Herbert Spencer (1960) el Estado, con su intervención, no debía perturbar las leyes de la vida económica, pues este cumple una función mínima de proteger la "libertad de los individuos" (p. 19) para que pueda producirse la evolución espontánea de la sociedad. Su orientación, como en los economistas clásicos, rechaza cualquier intervención en las leyes del mercado (fuerza motriz del proceso evolutivo) que pueda entorpecer la realización individual y la evolución social en su conjunto como expresión del desarrollo.

Desde su contexto alemán, en el cual el retraso del capitalismo era evidente, Max Weber (1864-1920) enfatiza en el papel del Estado para "acelerar la industrialización", y por ende el desarrollo del país. En su obra "Economía y Sociedad" parte de definir el Estado como "una comunidad humana que pretende y consigue el monopolio del uso legítimo de la violencia dentro de un determinado territorio" (Weber, 1971, p.54). Su limitación radica en que no tiene en cuenta la determinación clasista del Estado.

En la Economía Política de Carlos Marx, el Estado posee, como herramienta de dominación de clase, un lugar esencial en el propio devenir de la sociedad. De igual modo, el surgimiento del Estado fue examinado teóricamente por Engels (1963) en su obra "El origen de la familia, la propiedad privada y el Estado", en la que muestra cómo "el poder estatal se fue distanciando paulatinamente de la población, y va ejerciendo su dominación política de forma cada vez más violenta y sistemática sobre sus miembros" (...) (p.8), el poder político se concentrará en la figura del Estado. Engels (1963) sostiene la idea del Estado como institución que surge producto de las contradicciones entre clases propias de determinadas relaciones de producción, y a la vez resulta una institución facilitadora del desarrollo de esas relaciones de producción. El Estado es entendido como "una necesidad cada vez más ineludible" (p.10) para el desarrollo de la sociedad. 
V. I. Lenin (1870-1924), por su parte, señala que en:

La construcción socialista dominaría la propiedad social frente a la propiedad privada, el Estado asumiría un papel decisivo en la economía más allá de su lógico papel en la superestructura: la planificación del desarrollo económico y social frente al mercado que expresaba el dominio del hombre sobre su historia. (Como se cita en Figueroa, 2003, p. 20)

Otra de las aseveraciones realizadas en torno al Estado es aquella relacionada con las funciones que este cumple en la sociedad. Al respecto Arriagada (2006) precisa funciones tales como: provisión y producción de servicio (educación, salud, vivienda, seguridad social y otros); función financiera y compradora de servicios (asignación del gasto social y contratación y supervisión de servicios privados) y función reguladora de los aspectos institucionales (marco regulatorio tanto de las políticas sociales como de las económicas.

Vale destacar, como idea esencial acerca del Estado, lo relacionado con la supremacía que éste debe ejercer con respecto a la soberanía, control y coacción social:

Si el Estado pierde soberanía ante cualquier otro poder interno o externo, si no es capaz de tener pleno control de la administración pública ni del uso de la coacción a nivel social, si sus mecanismos actúan en contradicción unos con otros, pierde la capacidad de ser el principal instrumento que se requiere para la materialización de cualquier proyecto, acentuándose cuando se trata de realizar un proyecto social revolucionario en condiciones exteriores adversas como las que existen en el mundo contemporáneo. (Cabrera, 2006, p.17)

\section{Relación Estado-Familias}

(...) Al Estado y a otros organismos e instituciones sociales, les corresponde intervenir en los espacios de las familias, estimulando sus funciones y ofreciendo soluciones de apoyo por medio de políticas sociales, mecanismos legales y jurídicos, instituciones y prácticas concretas, al considerar que ella también constituye el ámbito en el que los individuos toman importantes decisiones sobre su vida, su trabajo y otras acciones que inciden en su bienestar. (Arriagada, 2006, p.23)

La perspectiva de familias investigada de manera relacional con el Estado se adentra a las influencias de las políticas en el desarrollo de las capacidades sociales y culturalmente determinadas para hombres y mujeres. De igual modo evaluar las reacciones de las familias como grupos sociales, dadas sus propias 
dinámicas de reproducción generacional, cuidado y mantenimiento de la fuerza de trabajo en la sociedad. Otros autores como Orozco (2005), se refieren a:

La responsabilidad que el Estado tiene de garantizar el bienestar básico de la población a partir de la premisa de la igualdad de oportunidades en la condición de ciudadanos(as), y por lo tanto de iguales en la sociedad en la cual se desenvuelve la existencia. (p.3)

Como nexo entre los cambios que se producen a nivel macro y microeconómico, es importante que con respecto al Estado:

Las familias sean pensadas como el espacio privilegiado para la acción de políticas sociales y aquel en que pueden tener mayor impacto. Desde la perspectiva estatal, la familia es una institución mediadora en las iniciativas vinculadas con la promoción de la equidad, con la garantía de los derechos humanos básicos y con la integración de los individuos en redes sociales y comunitarias. (Serrano, 2005, p.5)

No solo el Estado y las políticas sociales que establece, ofrecen impactos; de igual manera los comportamientos de las familias poseen efectos sobre ellos. El carácter activo de las familias, les confiere influir y cambiar cuando sea necesario y sean propicias las relaciones estatales hacia ellas, pues permanentemente las familias son productoras de estrategias de enfrentamientos a los problemas de la cotidianidad. Las políticas son resignificadas por los actores sociales y no sólo por los ejecutores, los que toman las decisiones.

Frente a la diversidad y complejidad en la que se van construyendo los vínculos familiares, las propuestas de nuevos programas y acciones tienen que ser indistintamente diversas y complejas, incorporando diagnósticos actualizados sobre sus situaciones y contando para la toma de decisiones de igual forma con la institución familiar.

De esta manera, el Estado no debe perder de vista en su proyección y prospectiva que las familias son sistemas sociales vivos que pierden o adquieren funciones, se estrechan o se alargan, según el contexto en que viven y se desarrollan, que como realidad vital son capaces de asumir nuevas formas y de regenerarse continuamente, sin estar exceptas de confrontaciones.

Es por ello, que las familias deben ser vistas y proyectadas como una relación social en la que "se configuren acciones recíprocas que impliquen intersubjetividad y conexiones estructurales entre sujetos" (Donati, 2003, p.50). 
Ello, reconociendo a su vez, que son reproductoras y/o creadoras de una cultura potenciadora del cambio y del equilibrio, del estado de las relaciones económicas, políticas y sociales existente. Además, modificando ya sea expandiendo o reduciendo con mayores o menores funciones, con mayor o menor estabilidad, según las características de la sociedad que las rodean, permitiendo ser instituciones y grupos sociales, perdurables y permanentes a la vez que el Estado las transforma.

A partir de este enfoque, es importante considerar la posibilidad real de la construcción de un encargo social del Estado que tienda a fortalecer sus responsabilidades hacia las familias como unidades de análisis integral y actores protagónicos fundamentales de los procesos de transformación que se dan a nivel social y grupal.

"Al Estado le concierne la promoción de la igualdad en las familias reconociendo a las nuevas familias reales, y no a las imaginadas desde el modelo patriarcal y post-patriarcal" (Hopenhayn, 2009, p.11). Además, incentivar en estas una transformación de los roles y poderes relativos de las partes que las componen, atacando y destruyendo las formas perversas de persistencia y mutación del modelo tradicional. También, es una tarea del estado promover mecanismos y mensajes relacionados con el enfoque de derechos específicos de género y generación en las familias, colectivizar una parte importante de las tareas familiares, apoyarlas precisamente en dichas funciones. Igualmente, ofrecer herramientas para la prevención, canalizándoles las disímiles problemáticas y brindarles apoyo material y espiritual.

Las tácticas del Estado hacia las familias, pudieran ser el camino para que sus responsabilidades se traduzcan en mejores estrategias para mejorar calidad de vida. Esto permitirá el cumplimiento de las funciones (bio-social, económica, cultural-espiritual) y la potenciación de su rol en los procesos de desarrollo y de reproducción social ( $r$ eproducción física de la población, de la fuerza de trabajo y de la ideología y la cultura).

Asimismo el Estado tiene el deber de propugnar determinados principios hacia las familias: valores, creencias, normas, que orienten y regulen sus vidas, 
basados en la igualdad, equidad, dignificación, integración social, democracia y libertad (liberación de cualquier clase de subordinación o dependencia en las relaciones familiares e independencia auténtica de hombres y mujeres). Lo anterior en post del desarrollo de reales procesos de participación y conciencia crítica de las familias frente a sus problemáticas y posibles vías de solución.

Del mismo modo, en el entramado institucional, los actores sociales se ocupan y sirven de medios eficaces para la concreción de los ideales de un proyecto social determinado a través de las funciones que desempeñan. Estos tienen su expresión inmediata en ministerios e instituciones y/o organizaciones de base, sindicatos, movimientos, partidos, fundaciones, gremios, escuelas, iglesias, medios de comunicación, agencias de cooperación internacional, organismos multilaterales, organizaciones no gubernamentales (O.N.G.). Estas entidades deben tributar de forma directa o indirecta al fortalecimiento de las familias a través de sus labores de orientación, prevención, canalización de problemáticas familiares y/o a través de su contribución al diseño, implementación, control y evaluación de políticas y servicios sociales que favorezcan a la institución y grupo familiar.

En el sistema político, el Estado es más o menos permeable a la influencia de los actores sociales, según las características que lo fundamentan: desde un tipo centralizador y autoritario, hasta un tipo descentralizador y democrático. En todos los casos, la intervención de los actores sociales debe ser juzgada a partir de su representatividad en el seno de la sociedad y de su poder, el que se manifiesta por su capacidad transformativa.

También el Estado cuenta con diferentes maneras y modos para ejecutar y poner en prácticas políticas y servicios (vías) de alcance social que posibiliten el bienestar de las familias. En este sentido, estas vías, también pueden diseñarse e implementarse de manera centralizadas y paternalistas $y / o$, facilitadoras, participativas dirigidas a provocar cambios en las familias en función de su emancipación y relaciones simétricas en su seno.

Existen en la literatura científica algunas construcciones en la definición de políticas familiares que se remiten a pensarlas como: 
El conjunto de medidas o instrumentos que intentan intervenir en el modelo de familia existente, tratando de "conformar" estructuras familiares para lograr un cierto modelo ideal de familia. Este ideal respondería tanto a los valores culturales dominantes como a una concepción de desarrollo económico y del papel que se le atribuye a la población en este modelo. (Goldani, 2005, p. 46)

Tales políticas, referidas a las familias, se entienden como el conjunto de medidas e instrumentos de políticas públicas cuyo objetivo es fortalecer las funciones que cumplen las familias. Se destacan entre ellas la reproducción y socialización de sus miembros, filiación y herencia, garantías de las condiciones materiales de vida, construcción de la subjetividad de sus integrantes (sistemas de valores, actitudes, ideologías y personalidades), políticas públicas orientadas para la familia.

Estas nuevas políticas partirían de una concepción amplia de familias y, al mismo tiempo, representarían una nueva articulación entre el trabajo para el mercado, el trabajo doméstico y la provisión de bienestar por parte del Estado.

El debate acerca de la inclusión de las familias para el diseño de las políticas sociales, debe tener presente siguiendo a Voghon (2010):

Con qué modelo o modelos de familia se operará para trazar posibles caminos de actuación, políticas no orientadas a individuos sino políticas públicas universales, solidarias, eficientes y democráticas orientadas a atender los derechos básicos de todos los ciudadanos y el logro de la igualdad y la democratización de la vida familiar, así como trascender la lógica de intervención que funciona bajo el criterio de programas o políticas sectoriales, desconectadas y desarticuladas, y concientizar en lo necesario de operar en sistemas, considerando las articulaciones entre lo estructural-subjetivo y lo universal-focalizado para las políticas orientadas a las familias. (p.15)

Asimismo, es vital la promoción de una política de Estado de familia o "política familiar" que posea como objetivo central la promoción del desarrollo sustentable de la nación que depende, de modo directo, del fortalecimiento de la familia como base de la sociedad. Una política familiar o política con "visión de familia" no puede prescindir de un enfoque integrador entre individuo y familia y familia e instituciones públicas, así como una mirada integral a la familia como objeto y sujeto de políticas sociales.

Lo que es evidente es que:

Los proyectos sobre las políticas sociales encaminadas hacia las familias deben encontrarse más cercanos a sus necesidades y especificidades, apuntando de igual 
manera hacia un mayor protagonismo familiar, como vía de fomento de prácticas democráticas, valorando el hecho de que las familias constituyen un ente heterogéneo, agentes de cambio íntegro, donde las acciones estatales deben ir encaminadas a ofrecer una agenda diversa de transformaciones económicas y sociales, con posibilidades de autonomía, implicación y participación de ellas. (Serrano, 2010, p.6)

Si las políticas sociales constituyen los modos a través de los cuales se priorizan las necesidades a satisfacer y se ordenan los medios para lograr el bienestar social de las familias y de la población en general, la puesta en práctica (o los instrumentos de estas políticas) se realiza a través de determinados medios o mecanismos concretos denominados: servicios sociales, que al encontrarse en contacto directo con la realidad social son también participantes en la política social.

Al decir de Setién y Arriola (2000):

Los servicios sociales se utilizan, se reciben, se hacen presentes a través de locales, personas, actuaciones, dinero. Son concebidos como la realidad en la que se concretan las políticas sociales, junto a su objeto de atención, definición de objetivos a cumplir, estructuración administrativa y de gestión de los mismos. (p.14)

"Están dirigidos con carácter integral a los ciudadanos, atendiendo a las necesidades y con la finalidad de mejorar sus condiciones sociales" (Setién y Arriola, 2000, p.14).

Se caracterizan por la gran diversidad de situaciones personales, familiares y sociales que se atienden, teniendo dentro de su campo de acción: la familia, la mujer, los adultos mayores, la juventud, la prevención de la delincuencia entre otras.

En este sentido, se acepta que su objetivo fundamental es lograr:

Una mayor calidad de vida y bienestar social para todas las familias, por medio de actuaciones de prevención, asistencia e inserción social a través del cumplimiento de funciones esenciales como la prevención, protección, rehabilitación, ayuda, a partir de la promoción de estrategias de actuación donde el protagonismo debe recaer en los propios implicados para estimular su capacidad de auto organización y de desarrollo de propuestas (Serrano, 2010, p.7).

Al respecto, urge señalar que el Estado para la concepción y puesta en práctica de políticas y servicios sociales concebidas para y desde el entramado familiar tiene que encontrarse en una permanente interrelación y retroalimentación con la realidad familiar. Además, que le permita conocer el estado real de las familias, la dinámica en la que se está moviendo, los cambios que se producen en 
su interior, sus contradicciones, preocupaciones, necesidades, prioridades, el impacto de las condiciones socioeconómicas y de las políticas y servicios sociales que se ponen en práctica, elementos que contribuirían a decisiones estatales acertadas, coherentes a tono con la dinámica social y familiar.

De ahí, que la atinada conexión entre responsabilidades del Estadoprincipios-vías-actores constituya un permanente reto del encargo social del Estado en relación con las familias.

\section{El encargo social del Estado en Cuba en relación con las familias}

En el devenir del proyecto social cubano a partir de las nuevas responsabilidades, principios, vías y actores sociales que asumió y desarrolló el Estado revolucionario, ha tratado de garantizar el bienestar de la población en general y de los miembros de las familias en particular.

De esta manera, el encargo social del Estado en relación con las familias comenzó desde los primeros años de la Revolución en el poder, a sustentarse en el logro de una real modificación de la estructura familiar. Igualmente, de sus condiciones de vida en el orden material y espiritual y en la formación de una nueva conciencia con respecto a las relaciones democráticas que deben primar en su seno en correspondencia con el ideal emancipador del proyecto social cubano. Por su parte, las familias sintetizan la coherencia de los cambios en todas las esferas que han tenido lugar en el país, respondiendo a las transformaciones sociales, evolucionando y modernizándose como resultado de la obra de la Revolución.

Desde la década de los sesenta, el Estado cubano promovió cambios sociales radicales, sus responsabilidades hacia las familias en particular y la población en general, se tradujeron en estrategias macro sociales con el fin inmediato de cumplir importantes compromisos sociales, económicos y políticos. Se establecieron nuevas responsabilidades hacia sus miembros, direccionadas hacia el cuidado y protección integral (jurídica, ciudadana, sustento económico, educativo, de salud, nutrición, vivienda, seguridad social, bienestar culturalespiritual). Estas responsabilidades se centraron en la concreción de diversos sistemas de atención, que ofrecen determinadas garantías, hacen valer sus 
derechos universales y elementales de seguridad y bienestar, y facilitan el desempeño de sus funciones.

El Estado fortaleció en los años que siguen al triunfo revolucionario el papel de las familias como células fundamentales de la sociedad, y les atribuyó responsabilidades, autoridad y funciones esenciales en la educación de las nuevas generaciones.

Para el cumplimiento de las responsabilidades estatales, el proyecto social cubano alternativo que se formaba y se consolidaba partió de determinados principios de carácter emancipador, revolucionario, popular, democrático y de integración social, siendo centro de atención la equidad, la justicia y el progreso social, dignificación del ser humano, igualdad de género, raza o nacionalidad, elevación del nivel de vida y homogenización social. De igual manera se fomentó una nueva moral en relación con los valores que debían regir en las relaciones familiares (fundadas en el amor, el respeto mutuo, la ayuda recíproca, la equidad, la responsabilidad compartida).

Al mismo tiempo, aseguró desde el nivel central la transmisión de políticas y servicios sociales para la redistribución nacional, garantizar la igualdad, así como el mantenimiento de altos niveles en las diferentes esferas de la sociedad. Por su parte, se establecieron actores sociales ${ }^{3}$ que aunque no tuvieron entre sus encargos funciones directas y específicas hacia las familias, sí tributaron en determinados objetivos y acciones.

\section{Retos actuales del Estado cubano en relación con las familias}

Como cualquier proyecto social en constante transformación y permeado de diferentes contradicciones en su devenir histórico, también el cubano, ha transcurrido por diferentes etapas o momentos.

Si importante para Cuba fue el viraje económico, social y político que produjo la revolución en 1959; no menos importante fueron los acontecimientos

\footnotetext{
${ }^{3}$ Federación de Mujeres Cubanas (FMC), Comités de Defensa de la Revolución (CDR), Partido Comunista de Cuba (PCC) Asambleas del Poder Popular (APPP) Centro Nacional de Educación Sexual (CENESEX), Central de Trabajadores de Cuba (CTC), Sociedades Científicas (sicólogos, juristas), Ministerio de Salud Pública, Radio y Televisión , otros institutos socializadores (escuela) entre otros.
} 
que se produjeron en el país a partir de 1989. La sociedad cubana no quedó inalterable frente a un escenario de tantas trasformaciones económicas e institucionales ${ }^{4}$. El esfuerzo de la población y el Estado por mantener en marcha la vida económica y social del país fue enorme.

La crisis económica de los noventa demandó del Estado una enorme labor dirigida a minimizar los efectos del debilitamiento económico intentando afectar lo menos posible sus garantías esenciales. El Estado tuvo que desarrollar numerosas reformas que abarcaron un amplio espectro que incluyó las de tipo económico, legales, políticas y sociales. Se destaca el cambio de prioridades en los sectores de desarrollo económico, autorización a la inversión de capital extranjero y de nuevas tecnologías. Se despenalizó la tenencia de divisas y autorización para el envío de remesas desde el exterior, el crecimiento y regulación del autoempleo o trabajo por cuenta propia, entre otras (Benítez, 2002, p.2).

$\mathrm{Si}$ bien estas medidas fueron inevitables como soluciones económicas, lamentablemente, también provocaron efectos sociales indeseados. La doble moneda provoca economías diferentes, acordes no ya al trabajo socialmente útil, sino a las posibilidades de acceder a la moneda libremente convertible.

Se fueron generando a su vez, franjas de marginalidad y asentamientos poblacionales en condiciones precarias y a la acumulación de necesidades no satisfechas en el momento de la aguda crisis. Reaparecieron al unísono otros males sociales que el proyecto transicional socialista había venido erradicando: desigualdades socio clasistas y territoriales, corrupción, delincuencia, prostitución, alcoholismo y el consumo de drogas entre otros.

A pesar de las dificultades señaladas, el desarrollo social no se detuvo; al contrario, se siguió exhibiendo hasta hoy, resultados imposibles de comprender desde la perspectiva del modelo neoliberal; los principios en los que se sustenta la nación tampoco han cambiado.

\footnotetext{
${ }^{4}$ A partir de 1986, comienza a producirse un retroceso en el ritmo de crecimiento económico, debido al agotamiento del modelo de producción extensivo que se venía utilizando, y al deterioro de las relaciones económicas con Occidente, derivadas a su vez de la suspensión del pago de intereses de la deuda, entre otras causas. Esto significó el preámbulo de la grave crisis económica que se acercaba.
} 
Igualmente, el entramado familiar no quedó inerte, por una parte, ante la imposibilidad de contar con la tradicional ayuda estatal, las familias siguieron siendo depositarias conscientes 0 inconscientemente con más o menos preparación de determinadas responsabilidades individuales, a la vez que han asumido y desarrollados disímiles estrategias ${ }^{5}$. Por otro lado, el acelerado proceso de transición demográfica y las modificaciones producidas en el sistema de valores de la sociedad provocaron cambios en los patrones de formación, ampliación y disolución de las estructuras familiares en Cuba; La multiplicidad familiar viene expresando cambios sustanciales en relación al matrimonio, el envejecimiento, fecundidad etc., aspectos que también han demandado del Estado, una readecuación de ciertas responsabilidades que venía implementando hacia la institución y grupo familiar.

Tocante a los tipos de familia, los cambios socio demográficos, las transiciones sociales y culturales han producido de manera general una ruptura del modelo de familia nuclear, biparental, conyugal y heterosexual; fenómeno que se le ha llamado en denominar diversidad y complejidad familiar. Complejidad en el sentido de ruptura contracultural de los ejes de vinculación considerados otrora como naturales tales como el parentesco y la conyugalidad. Por otra parte, la heterosexualidad, en el que la familia incluye vínculos monoparentales, no consanguíneos, no legales, y no solo heterosexuales con lo que se asocia el modelo patriarcal (Arés y Benítez, 2009).

Según datos del último Censo de población y vivienda (2002) se observa una disminución de hogares nucleares ${ }^{6}$, con padre, madre e hijos, aunque todavía

\footnotetext{
${ }^{5}$ Para los inicios de la pasada década se conoce que las estrategias familiares apuntaban hacia cuatro direcciones principales: elevación de los ingresos monetarios provenientes del trabajo asalariado; satisfacción de necesidades con los recursos disponibles; empleo de redes formales e informales de relaciones de ayuda y cooperación, incremento de relaciones de pareja con personas procedentes de otros países).

Hoy aparece con mayor fuerza el sector no informal de la economía denominado cuentapropismo o trabajo por cuenta propia (TCP), denominada así a la actividad económica que se realiza en el sector informal de la economía para la producción de bienes y los servicios por unidades económicas muy pequeñas, utilizando distintos medios. En la actualidad, muchas familias se convierten en familias cuentapropistas con la intensión de elevar sus ingresos.

${ }^{6}$ Con cierto predominio del tipo de familia nuclear, estudios apuntan que el cambio más significativo entre 1953 y 1981 fue la importante disminución del tamaño promedio de los núcleos de 4,9 a 4,1 personas, como promedio nacional ello se asocia a los planes constructivos de viviendas impulsados
} 
predominan los domicilios de este tipo. Han proliferado también los hogares multigeneracionales. Se aprecia también un incremento de familias monoparentales con jefatura femenina, como resultado de divorcios o a la no implicación de la figura paterna. Se encuentran presente las nucleares monoparentales con o sin ayuda del padre no custodio, monoparentales extensas, ensambladas, extensas compuestas, hasta las convivencias múltiples como albergues y solares, así como los llamados hogares unipersonales. Algunos datos confirman que aproximadamente el $32 \%$ de los hogares son de tipo extenso y compuesto, aparece el fenómeno de la trigeneracionalidad 0 cuatrigeneracionalidad, con ancianos que van a vivir con los hijos $u$ otros parientes adultos o pasan a ser dependientes de los mismos (Alfonso, 2010).

Con respecto al matrimonio, específicamente el legal, en todos estos años ha ido perdiendo importancia, la tasa bruta de nupcialidad se ha visto resquebrajada. En 1990 fue de 17,7, en 1992; 12,4 en 1993 y 10,7 en 1994.

A partir de 1995 vuelve a descender alcanzando valores inferiores a 1981: 6,4 en 1995; 5,9 en 1996; 5,1 en 1999 y 2002; y 4,9 en el 2003 (Álvarez, 2000). Al mismo tiempo se evidencia la existencia de una variedad de formas de convivencia y una tolerancia creciente a las mismas (destacándose la convivencia sin matrimonio o uniones consensuales como alternativa para la formación de familias, miedo al compromiso, al fracaso matrimonial). La convivencia a prueba se ofrece como una transición menos comprometida para los que anticipan que la ruptura puede ocurrir) ${ }^{7}$.

por el Estado y los bajos niveles de fecundidad que tuvo lugar en el país, las familias nucleares en 1981 constituían el 53,7 \%, las familias extendidas disminuyeron al 32,5\%. A pesar de la mayor proporción de familias nucleares y de la hipótesis acerca de la presumible tendencia a la nuclearización, los especialistas alertaron, desde entonces, acerca del probable incremento futuro, tanto en cifras absolutas como relativas, de las familias extendidas, debido a la insuficiente construcción de viviendas.

${ }^{7}$ Se advierte la aparición de actitudes ante el divorcio más abiertas que en el pasado y un menor dramatismo en su valoración entre las generaciones más jóvenes. Se han incrementado las familias monoparentales con jefatura femenina, como resultado de divorcios o a la no implicación de la figura paterna. El $70 \%$ de los niños cubanos tienen a sus padres divorciados, nupcialidad reincidente, que no siempre es legal, reorientación familiar de personas de igual sexo. Son frecuentes las uniones de personas homosexuales, que en muchos casos tuvieron hijos con anterior casamiento heterosexual y conviven de forma estable. 
Hay que destacar que aunque existe una diversidad de formas de convivencia, las uniones siguen teniendo importancia, la vida en pareja sigue siendo una opción del cubano.

Otro fenómeno que tiene lugar es la nupcialidad reincidente, que no siempre es legal. Se ve a los hijos de los matrimonios anteriores asistiendo a la boda de sus padres por segunda o tercera ocasión. También en Cuba existe otra tendencia que es internacional: la reorientación familiar de personas de igual sexo. Son frecuentes las uniones de personas homosexuales, que en muchos casos tuvieron hijos con anterior casamiento heterosexual. También están presentes, producto de la emigración externa, las uniones de parejas desde la distancia.

La emigración externa, evoluciona de diferente forma a lo largo de estos años, y las consecuencias de estos movimientos para las familias cubanas también son diferentes en los distintos momentos: desde la ruptura de vínculos de relación a inicios de la Revolución, hasta la búsqueda de los lazos perdidos en la década de los noventa y en la actualidad. Sin dejar de reconocer la influencia que provoca en la transmisión de valores correspondientes a modos de vida diferentes del que predomina en la sociedad, el surgimiento de expectativas materiales de consumo que transcienden las posibilidades que existen en el país, además del afianzamiento de las diferencias sociales entre otras (Díaz, Durán, Váldez, Chávez y Alfonso, 2001), hoy se percibe por una parte de las familias como una estrategia adecuada de enfrentamiento a la crisis.

En relación con la fecundidad, desde 1978 las parejas cubanas están teniendo una cantidad de hijos menores que los 2,1 alumbramientos promedio por mujer, necesarios para garantizar que haya un reemplazo generacional. Ello ha incidido directamente en el tamaño y la composición de la familia. En este sentido, la prevalencia de los métodos anticonceptivos y la frecuencia del aborto inducido constituyen, en ese orden, los principales determinantes del descenso de la fecundidad cubana en las últimas décadas.

Del mismo modo, están presentes otros elementos explicativos, como la notable reducción de la mortalidad infantil, con una frecuencia de 4,7 defunciones de niños menores de un año por cada mil nacidos vivos en el año 2008. A partir de 
1989 -año que marca la pérdida del ámbito del comercio internacional de Cuba y el inicio de severas contracciones en las economías familiares-, es probable que las consideraciones de las familias acerca de las dificultades cotidianas hayan comenzado a desempeñar también un papel de importancia en la regulación de los nacimientos (Arés y Benítez, 2009).

Coincidiendo con estas autoras, otras investigaciones señalan que el comportamiento general de la fecundidad cubana en los años noventa indica que, si no como una estrategia consciente de enfrentamiento, al menos como una respuesta adaptativa a la crisis económica. La familia cubana ha optado por disminuir su descendencia, con lo cual el tamaño medio del hogar se ha reducido hasta 3,3 personas (Díaz et al., 2001).

Sin embargo, a partir de 2006 se acentúa la tasa de fecundidad en adolescentes de 15 a 19 años con 41,8\% por cada mil chicas de esa edad, hasta el 2010 que alcanzó el 55, 4\%, dado fundamentalmente, según reporta el especialista (Álvarez 2000), por la falta de educación sexual y desconocimiento de los métodos de control de la natalidad. Esto, a pesar de que en el país se viene priorizando la educación sexual, el conocimiento y acceso a los anticonceptivos y la planificación familiar, a la vez que constituye un objetivo de desarrollo para el milenio.

Otras problemáticas de índole demográfico que se agudizan y que tienen que ver con cambios poblacionales acelerados lo constituye el proceso de envejecimiento de la población cubana, lo que provoca cambios estructurales (incremento de hogares unipersonales de ancianos que se han quedado solos y que tienen bajos recursos, ancianos cuidando a ancianos, por lo que se inicia así una nueva etapa del ciclo vital de la familia, arreglo de convivencia entre una pareja joven y ancianos con los que no tienen una continuidad biológica, proliferación de hogares multigeneracionales, reconfiguración del rol de los abuelos) (Arés, 2007; Chávez, 2005).

Según datos publicados por la Oficina Nacional de Estadística (ONE), el crecimiento demográfico ha sido negativo en los años comprendidos entre 2006 y 2008. Dichos desafíos demográficos (Alfonso, 2010) afectan de manera inmediata 
la esfera de la producción material y otras áreas como son la salud, los servicios y la seguridad social. Igualmente la población rural cubana se enfrenta a un crecimiento poblacional, que se expresa en un aumento del $13 \%$ en el año 2000 comparado con 1990 y alcanza aproximadamente el valor del $15 \%$ en el año 2008.

De igual manera, está presente una dinámica de las relaciones familiares que son hoy más flexible, y existe por ello, un margen para el intercambio de roles. Sin embargo, en el plano de las relaciones familiares, cada familia está haciendo experimentos en torno a un patrón de grupo que vive en un terreno desconocido. En el curso de este proceso muchas familias fracasan por completo, y así contribuyen al desequilibrio de la compleja y cambiante sociedad. Otras familias por el contrario obtienen notables éxitos y fomentan en el seno de la vida familiar, patrones de conducta que llegan a constituir satisfactorios ajustes al mundo presente y al cambio social mismo.

Junto a la necesidad de readecuar las responsabilidades estatales entorno a las familias, las políticas y los servicios sociales (vías), deben seguirse pensándose y proyectándose de manera integradas, orientadas a la prevención, educación, fortalecimiento de sus funciones y enfrentamiento a disímiles problemáticas en el ámbito familiar.

Al respecto, es importante puntualizar las aportaciones que varias investigaciones de las ciencias sociales cubanas han ofrecido en relación a la necesidad de implementar, perfeccionar, consolidar e instituir políticas, servicios y programas atemperados a las nuevas realidades, encaminados a enfrentar los retos poblacionales del futuro cercano (Arés y Benítez, 2009), dirigidas a los distintos tipos de familias que conviven en la sociedad cubana actual (Zabala, 2000). Políticas no solo asistencialistas sino desarrolladoras de protagonismo familiar en la solución de sus necesidades (Arés y Benítez, 2009), políticas diferenciadas para aquellos tipos de familias que de acuerdo con su condición de vida, no posean posibilidades reales de acceso a medicamentos muy costosos, etc. (Chávez et al., 2010), programas educativos y de orientación social que refuercen la función socializadora de la familia (Díaz et al., 2001). 
Los estudios revelan la necesidad de instituir servicios de atención y orientación a parejas y familias en situación de conflicto que soliciten ayuda para enfrentar dificultades derivadas de la convivencia (Díaz et al., otros, 2001). Crear una entidad estatal de alto nivel jerárquico -o elevar la jerarquía institucional de alguna ya existente- que represente los intereses de la familia, promueva su desarrollo, y coordine las políticas, investigaciones y acciones prácticas dirigidas a este grupo social. (Díaz et al., 2001). Desarrollar sistemas de servicios en general, y de apoyo al hogar en particular, que contribuya a una mejor compatibilización de las obligaciones laborales con el cumplimiento de las funciones familiares. Establecer un Banco de Datos sobre la familia cubana, ampliar los programas de construcción y conservación de viviendas, tanto por vía estatal como por esfuerzo propio de las familias. Prestar atención, fundamentalmente, a familias que vivan albergadas, en condiciones de hacinamiento, y con deterioro avanzado de sus viviendas Destinar una parte especial de esos programas a parejas jóvenes en fase de ampliación de la familia, por constituir la principal fuerza reproductiva del país (Díaz et al., 2001)

Además, desde los actores sociales presentes en la sociedad cubana, pudiera potenciarse acciones que favorezcan a las familias, tal es el caso de los Comité de Defensa de la Revolución (CDR) a partir de la utilización de espacios comunitarios para debatir sobre temáticas referidas a normas de convivencia, respeto, solidaridad. Esta organización de masa debe lograr un funcionamiento eficiente y eficaz que responda a las necesidades e intereses sociales de las familias, pues no es menos cierto que los métodos que en los últimos años la organización ha desarrollado le han restado credibilidad, mostrando formalismo e inercia.

Las Asambleas del Poder Popular (APPP) como medio de la actividad política del país que representan los intereses de la sociedad cubana en su conjunto, pueden ejercer mayor influencia en el diseño y la ejecución de adecuadas vías que abarquen a la institución familiar a través del fortalecimiento del papel del municipio y del establecimiento y control de una estrategia municipal que integre a los diferentes actores que aparecen en el tejido social local. 
La Central de Trabajadores de Cuba (CTC) a través del fortalecimiento de la participación de sus afiliados en la toma de decisiones y en la reflexión sobre determinadas realidades familiares, pudiera ofrecer respuestas y/o canalizar a algunas de las problemáticas presentes en el entramado familiar más inmediato.

Las Sociedades Científicas (sicólogos, juristas), que poseen la particularidad de alertar, recomendar, asesorar a las instancias gubernamentales con recomendaciones científicas relacionadas entre otras temáticas con los asuntos de familia, deben procurar con mayor ahínco que los resultados e implementación de las recomendaciones en relación con las familias que se formulan en dichas investigaciones, no sean engavetados por parte de los decisores.

En relación a la escuela, constituyen retos esenciales, la continua y profunda preparación de maestros y profesores acerca de conocimientos sobre las características de las etapas del desarrollo de los estudiantes. Así como el modo de implementación del trabajo preventivo, elaboración de materiales divulgativos y didácticos relativos a la vida familiar y su adecuado desarrollo, empleo de métodos educativos adecuados para sancionar conductas reprobables, sistemática comunicación con las familias, funcionamiento de las escuelas de padres, existencia de programas educativos que contribuyan al perfeccionamiento de la vida familiar.

Institutos como el de Radio y Televisión, pueden favorecer mucho más, en acciones hacia el entorno familiar a través de espacios radiales o televisivos que contengan como objetivo esencial temas vinculados al perfeccionamiento de la vida familiar, equidad de género, violencia intrafamiliar, solución de conflictos, adecuadas relaciones intergeneracionales etc, logrando una mayor coherencia entre los productos que ofrece y las realidades familiares.

En materia jurídica son indudables los logros que ostenta Cuba respecto a la familia (reconocimiento de uniones consensuales, igualdad de los hijos con independencia de la forma de unión, etc.). De esta forma se han legislado temas relacionados con el matrimonio, las relaciones familiares, el papel de la mujer dentro y fuera de la familia, la educación y crianza de los niños, el divorcio, la 
ilegitimidad, la sexualidad, derechos de sucesión, los cuales quedaron explícitamente plasmados en el Código de Familia (1975, modificado en 1977) ${ }^{8}$ y en el Código de la Niñez y de la Juventud $(1978)^{9}$ que regularon, de manera equitativa y humana las relaciones en el hogar.

Sin embargo, desde el punto de vista legal los mayores desafíos están encaminados a suplir vacíos e insuficiencias en el cuerpo de leyes y normativas vinculadas a la familia como unidad o grupo que exige un tratamiento particular; actualización del código de familia, ya que en el cuerpo de las leyes persisten asimismo estereotipos de género, etc. De ahí la importancia de revisar el enfoque de género en las leyes, modificar el marco legal y sus procedimientos, atendiendo a las nuevas realidades sociales (migración, violencia intrafamiliar, patria potestad, responsabilidad paterna, etc.

Ante las realidades presenten en la sociedad cubana actual, el Estado enfrenta el reto no solo de continuar cuidando y ofreciendo derechos a sus miembros. Asimismo debe perfeccionar sus responsabilidades en garantías y protecciones a las familias pero en su integralidad, ajustando los beneficios que puede ofrecer desde la diferenciación y especificidad familiar, partiendo no solo de las necesidades reales de las familias, sino también de sus potencialidades. Todo esto, a través de acciones que permitan corregir prácticas igualitaristas, asistencialistas y homogenizadoras aún presentes en la transición socialista cubana (Serrano, 2010).

\section{Reflexiones finales}

Ofrecer seguridad, confianza y los medios necesarios para la adecuada relación entre sus miembros y la sociedad a la heterogeneidad familiar presente hoy en el proyecto social cubano en la integración del bienestar material y espiritual constituye hoy un gran desafío.

\footnotetext{
${ }^{8}$ Entre sus objetivos se encuentra el de fortalecer la familia y contribuir al cumplimiento por los padres de sus obligaciones con respecto a la protección, formación moral y educación de los hijos.

${ }^{9}$ Regula los deberes y derechos de la joven generación y las obligaciones de las personas, organismos e instituciones que intervienen en su formación integral, constituyéndose en un valioso instrumento educativo al contener un conjunto de normas y principios morales que deben servir de guía en su conducta social.
} 
Los retos que afronta la sociedad cubana no solo hacia adentro, sino hacia fuera vuelven a recordar el carácter universal por su sustancia del proceso revolucionario cubano.

Las transformaciones en el plano interno que se vienen produciendo desde más de una década en el país hacen que la sociedad cubana sea muy diferente a la que se presentaba en la década de los 80 . La realidad cotidiana con sus contradicciones presenta la necesidad imperiosa de fortalecer, rescatar, conceder desde el Estado a las familias recursos de comunicación, solución de conflictos, redistribución del poder, asignación equitativa de roles, reafirmación de valores como la solidaridad, la reciprocidad, el respeto la no violencia la responsabilidad familiar y social entre otros aspectos de carácter material y objetivo.

Redefinir el encargo social en relación con la familia desde la concatenada relación entre responsabilidades estatales, principios, vías y actores sociales se convierte en una necesidad vital.

Ante la contradictoria realidad social cubana, propia de la espiral dialéctica del desarrollo, una nueva mirada desde el Estado con respecto a su encargo social en relación con las familias requiere aprovechar las potencialidades del proyecto social esencialmente humanista. Dichas, potencialidades deben ser desplegadas para la actividad cooperada y participación tanto de los decisores de ese encargo social como de la institución familiar y de ambos entre sí.

El sostenido perfeccionamiento de la sociedad transicional junto a la actualización del modelo económico, se convierte en un desafío permanente, y en una obligatoriedad la preservación de la igualdad de derechos e igualdad de oportunidad para todos los ciudadanos ${ }^{10}$, mejoras en el nivel de vida de las familias mediante el incremento de la producción y los servicios unido a una eficiente gestión y participación real de las familias en la toma de decisiones del Estado en relación con ellas.

El país tiene condiciones sin precedentes para aspirar a familias mejores, a pesar de sus difíciles condiciones económicas y los problemas sociales que aún subsisten. Muchas conquistas a las que aspiraría cualquier país subdesarrollado,

\footnotetext{
${ }^{10}$ Lineamientos de la política económica y social. VI Congreso del PCC
} 
en Cuba ya están logradas. El empeño ahora es no perder la vigencia del ideal posible de sociedad y familia que se quiere, en pos de seguir construyendo y apostando a la esperanza de un encargo social del Estado en relación con las familias emancipador en un nuevo contexto histórico.

Continuar avanzando en las transformaciones familiares teniendo en cuenta sus particularidades constituye un desafío esencial para el encargo social del Estado. Es apremiante construir la verdadera cultura de la igualdad, formar mujeres y hombres nuevos, cultos y libres, aptos para asumir con preparación, responsabilidades y tareas en la pareja, en la familia, en la sociedad (Serrano, 2010).

\section{Referencias Bibliográficas}

Álvarez M. (2000). Situación de la niñez, adolescencia y la familia en Cuba. La Habana: Editorial de la Mujer.

Alfonso León, Alina. (2010). Respuestas de salud en la tercera edad. Revista electrónica Novedades en población. Centro de Estudios Demográficos de la Universidad de la Habana (CEDEM), No. 1, 1-17.

Arés, P (2007). Familia cubana, realidad económica y políticas sociales. Fortalezas y desafíos. Informe de Investigación. La Habana: Dpto. de Sicología. U.H.

Arés, P y Benítez, M. E. (2009). Elementos a considerar para el diseño de una política familiar en Cuba. Informe de Investigación. La Habana: Dpto. de Sicología. U.H y CEDEM.

Arriagada, I. (2006). Cambios de las políticas sociales: políticas de género y familia.

División de Desarrollo Social, CEPAL. Santiago de Chile. Recuperado de http://www.eclac.org/publicaciones/xml/3/24453/sps119 Icl25.pdf

Benítez, M. E. (2002). Cambios socio demográficos de la familia cubana en la segunda mitad del siglo XX. La Habana: Centro de Estudios Demográficos UH. Recuperado de

http://www.cedem.uh.cu/Catalogo Biblioteca/document/PD/Cambios sociodemogr aficos de la familia cubana.pdf 
Cabrera, C. (2006). La teoría de la transición al Socialismo: algunas consideraciones sobre el proceso de su conformación y proyección actual. En Selección de lecturas de Sociología Política. Tomo 2. La Habana: Editorial Félix Varela.

Constitución de la República de Cuba, reformada constitucionalmente en 2002. Aprobado en sesión extraordinaria de la V Legislatura de la Asamblea Nacional del Poder Popular, celebrada los días 24, 25 y 26 del mes de junio del 2002.

Comte, A. (1957). A General View of Positivism, Nueva York: R Seller.

Chávez, Ernesto Negrín. (2005). "Consideraciones socio demográficas relativas a las familias cubanas contemporáneas". Ciudad de La Habana: Centro de Investigaciones Psicológicas y Sociológicas (CIPS).

Chávez, E; Durán, A; Valdés, Y; Gazmuri, P; Díaz, M; Padrón, S; Perera, M (2010). Las familias cubanas en el parteaguas de dos siglos. Centro de Investigaciones Psicológicas y Sociológicas (CIPS).CITMA.

Díaz, M; Durán, A; Valdés, Y; Chávez, E; Alfonso, T. (2001). Familia y cambios socioeconómicos a las puertas del nuevo milenio". (Informe final de investigación). La Habana: CIPS. Centro de Investigaciones Psicológicas y Sociológicas.

Donati P. (2003). Manual de Sociología de la Familia. España: Ediciones Universidad de Navarra. S.A Instituto de Ciencias para la familia. Pamplona.

Durkheim, E. (1931). El Socialismo. Barcelona: Editorial Apolo, Flores 16.

Engels F. (1963). El Origen de la Familia, la Propiedad Privada y el Estado. La Habana: Ediciones. Política, prefación a la IV Edición 1891.

Engels F. (1974). La situación de la clase obrera en Inglaterra. La Habana: Editorial de Ciencias Sociales.

Espina, M. (2008). Mirar a Cuba hoy: cuatro supuestos para la observación y seis problemas-nudos. Temas, N. 56, 8-14.

Figueroa Albelo, V. M. (2003). Ensayos de Economía Política de la transición extraordinaria al Socialismo en la experiencia de Cuba. UCLV.

Fung, T. y Rodríguez, C. C (2000), Acerca del Sistema Político. En Selección de temas de Teoría Sociopolítica, tomo II. Editorial Félix Varela, La Habana. 
Goldani, L. (2005). "Reinventar políticas para familias reinventadas: entre la "realidad" brasileña y la utopía", en Irma, Arriagada (coordinadora), Políticas hacia las familias: protección e inclusión social. CEPAL, División de Desarrollo Social, Naciones Unidas, Santiago de Chile.

Hopenhayn M. (2009). Familias: igualdad, derechos y derecho a la igualdad. En Las familias latinoamericanas interrogadas. Hacia la articulación del diagnóstico, la legislación y las políticas. CEPAL. Santiago, 29 y 30 de octubre.

Orozco, M. O. (2005). Las dimensiones políticas en el desarrollo de las familias. En VI conferencia iberoamericana las familias y las culturas, Hacia la reafirmación de la identidad cultural (pp 26-35). La Habana. Cuba.

Kaplan, M. (1969). Macro politics. N. Y, p 25.

Lenin, I.V. (1986). El Estado y la Revolución. Moscú: Editorial Progreso.

Parsons, T (1966). El sistema social. Madrid: Editorial Castilla, 1966.

Setién L y Arriola J. (2000), Política social y servicios sociales, en Carmen Alemán Bracho y Jorge Garcés Ferrer (coordinadores), Políticas sociales, Madrid: Editorial Cristina Casado Lumbreras.

Spencer, H. (1960). Las inducciones de la Sociología y las Instituciones Domésticas. La España Moderna. Madrid: S/A.

Serrano, Y. (2005). Propuesta de una estrategia de desarrollo comunitario a través de un diplomado sobre familia y género en la UCLV, en IV Encuentro Iberoamericano de Comunicación Social de la Ciencia, Innovación Tecnológica y Medio Ambiente. CITMA. La Habana.

Serrano, Y. (2010). El enfoque comunitario y las políticas públicas hacia la familia cubana. III Taller Internacional sobre Juventud. CIPS. La Habana.

Spencer, H (1960). Las inducciones de la Sociología y las Instituciones Domésticas. La España Moderna. Madrid, S/A.

Valdés, J (2000). El sistema político cubano de los años noventa: continuidad y cambio, En Manuel Monereo (coordinador). "Cuba construyendo futuro". Madrid: El Viejo Topo. 
Voghon, R. (2010). El enfoque de familia en la política cubana actual, en Reina Fleitas y Rosa Ma. Voghon (coordinadoras). Selección de Lectura de "Sociología de la familia". La Habana. UH.

Weber M. (1971). Economía y Sociedad, Capitulo I. Tomo I. La Habana: Ediciones. Ciencias Sociales, Instituto del Libro.

Zabala, MC. 2000). Las familias cubanas: Principales tendencias en su desarrollo. FLACSO, Cuba. 